\title{
Effect of low birth weight on childhood asthma: a meta-analysis
}

\author{
Xue-Feng Xu' ${ }^{1}$, Ying-Jun Li ${ }^{2}$, Yuan-Jian Sheng ${ }^{1}$, Jin-Ling Liư ${ }^{1}$, Lan-Fang Tang ${ }^{1}$ and Zhi-Min Chen ${ }^{*}$
}

\begin{abstract}
Background: Low birth weight is strongly correlated with an increased risk of adult diseases. Additionally, low birth weight might be a risk factor for asthma later in life.

Methods: A systematic literature search of the PubMed database from 1966 to November 2013 was conducted. The criteria for inclusion of papers were as follows: case-control or cohort studies; the odds ratio (OR) or risk ratio (RR) estimates with the corresponding 95\% confidence intervals (Cls) were presented, or there were sufficient data for calculation; and studies were published in English up to October 2013. Random-effect and fixed-effect meta-analyses, meta-regression, and cumulative meta-analysis were conducted.

Results: Thirteen cohort studies and 1,105,703 subjects were included. The overall pooled RRs (95\% Cls) of asthma risk for low birth weight were 1.162 (fixed-effects model, 95\% Cl, 1.128-1.197) and 1.152 (random-effects model, 95\% Cl, 1.082-1.222). In stratified analyses, the effect of low birth weight on childhood asthma was strong, particularly in studies conducted in Europe, those with a small sample size, and those published recently. A meta-regression analysis did not find significant determinants.
\end{abstract}

Conclusions: This meta-analysis shows that low birth weight significantly increases the risk of childhood asthma.

Keywords: Birth weight, Childhood asthma, Meta-analysis, Systematic review

\section{Background}

Asthma is a serious global health problem. Worldwide, an estimated 300 million people are affected by asthma. The global prevalence of asthma ranges from 1 to $21 \%$ of the population in different countries [1]. The prevalence of asthma is increasing in most countries, especially among children [2]. This increase may be closely associated with exposure to allergens (particularly pollens, molds, dust, and pet dander), tobacco smoke, exercise, air pollutants, and respiratory infections, but has yet to be fully explained [3]. Furthermore, children with low birth weight are prone to developing decreased respiratory function and having an increased risk of chronic respiratory symptoms during childhood [4]. Previous studies have shown that some prenatal or perinatal adverse factors could be associated with the development of asthma later in life [4-6].

\footnotetext{
* Correspondence: drchenzm@163.com

'Department of Pulmonology, The Children's Hospital, Zhejiang University

School of Medicine, Hangzhou 310003, China

Full list of author information is available at the end of the article
}

The fetal origins of adult disease hypothesis proposes that fetal adaptation to an adverse intrauterine environment could lead to permanent changes in individual physiology and metabolism [7]. There is evidence that lower birth weight is strongly correlated with an increased risk of adult diseases, such as type 2 diabetes mellitus, hypertension, and cardiovascular disease. Additionally, impaired fetal growth is a risk factor for asthma later in life [8], especially in children with a very low birth weight [9]. However, previous studies on the relation between low birth weight and childhood asthma have provided controversial results. To the best of our knowledge, there are no previous systematic reviews that have estimated the overall effect of low birth weight on the risk of childhood asthma. Therefore, we conducted a systematic review and a meta-analysis of the existing evidence on the relation between low birth weight and the risk of childhood asthma.

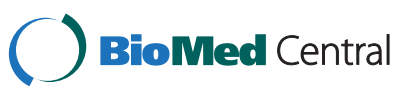




\section{Methods}

\section{Search strategy and inclusion criteria}

We performed a systematic literature search of the PubMed database from 1966 to November 2013 using the following search command: birth weight and "asthma or wheezing or wheeze". The abstracts identified by this search were screened to eliminate the obviously irrelevant abstracts (such as reviews, systemic reviews, and case reports). The criteria for paper inclusion were as follows: (i) case-control or cohort studies that focused on the association of low birth weight with childhood asthma (less than 16 years old); (ii) studies that presented the odds ratio (OR) or risk ratio (RR) estimates with the corresponding 95\% confidence intervals (CIs), or sufficient data for calculation; (iii) normal birth weight as the reference category; and (iv) studies published in English up to October 2013. All publications providing sufficient information regarding the relation between low birth weight and childhood asthma were included, irrespective of whether this issue was their primary or secondary objective. We excluded studies that used asthma-like symptoms or other manifestations of respiratory impairment as an outcome, such as wheezing.

The outcome of interest was childhood asthma. The definition of asthma was based on a physician's diagnosis, or a history of asthma reported by their parents. Our primary predictor variable was low birth weight, which was defined as a birth weight of less than 2500 g. For any study to be included in the present study, its outcome and predictor definitions had to be consistent or adaptable with our definitions. Both outcome and predictor variables were dichotomous.

\section{Data extraction}

Four investigators independently carried out data extraction of the following items: authors, publication year, study design, country, population age, diagnosis of asthma, adjustment for confounding (family history, air pollution, sex, gestation age, smoking, and caesarean etc.), and effect size and corresponding estimates with 95\% CIs. Two reviewers completed the quality assessment independently. A set of structured criteria modified from previous studies (Newcastle-Ottawa scale for cohort study) were used to complete the quality assessment of publications. A higher score indicates higher quality. In the case of disagreement of extracted data, discrepancies were resolved by discussion and achieved consensus.

\section{Statistical analysis}

We abstracted the multivariate-adjusted risk estimates (OR or RR). The unadjusted risk estimates were calculated using original data when the adjusted was unavailable.
The CIs were transformed to a log scale and then the standard error was calculated. A pooled summary relative risk was calculated according to the fixed-effects model and a random-effects model. Statistical heterogeneity was assessed with the I-squared $\left(\mathrm{I}^{2}\right)$ value, which represents the percentage of total variation across different studies due to heterogeneity rather than chance. $\mathrm{I}^{2}$ values of $25 \%$, $50 \%$, and $75 \%$ have been related to low, moderate, and high heterogeneity, respectively [10]. A random-effects model was applied when there was notable heterogeneity ( $\mathrm{I}^{2}$ index $\geq 50 \%$ ), and otherwise, the fixed-effects model was used. Subgroup analyses were stratified by geographic area and adjusted for the major confounder. Meta-regression analysis was used to investigate the potential sources of heterogeneity. Cumulative metaanalysis in the order of publication year was conducted to check homogeneity of the results. Publication bias was assessed by using the funnel plot, the rank correlation test, and the graphical test [11-13]. All statistical analyses were carried out by STATA version 12.0 (Stata Corp., College Station, TX).

\section{Results}

\section{Characteristics of included studies}

A description of the search process is shown in Figure 1. Of the 692 papers found by the search, 13 cohort studies met the inclusion criteria and were included [14-26]. Among these, only five studies provided the adjusted effect estimates of low birth weight versus childhood asthma [14-16,22,23]. Of the 13 cohort studies selected, 11 were published in 2000-2013, and two were published in 1997 and 1998. The majority of the cohorts $(n=6)$ were in Europe (Denmark, Finland, Germany, Sweden, and the United Kingdom) [14,16,20,21,24,26]. Four cohorts were studied in North America (US and Canada) $[19,22,23,25]$, one in Oceania (New Zealand) [17], one in South America (Brazil) [15], and one in Asia (Taiwan) [18]. Detailed characteristics of the studies that were included are shown in Table 1.

\section{Exposure, outcome, and effect measures}

Eleven studies used the definition of low birth weight compatible with our criteria $(<2500 \mathrm{~g})$. Birth weight in the other two studies was less than $3000 \mathrm{~g}[16,18]$. General variance-based methods using CIs were applied to combine the results according to birth weight. The definition of asthma was based on a physician's diagnosis. Children with wheeze or wheezing were excluded.

Two studies reported data for the effect of low birth weight on the risk of future asthma as adjusted ORs $[14,16]$. These studies used multivariate logistic regression to obtain results. The other three studies presented adjusted RRs. The rest of the eight studies 


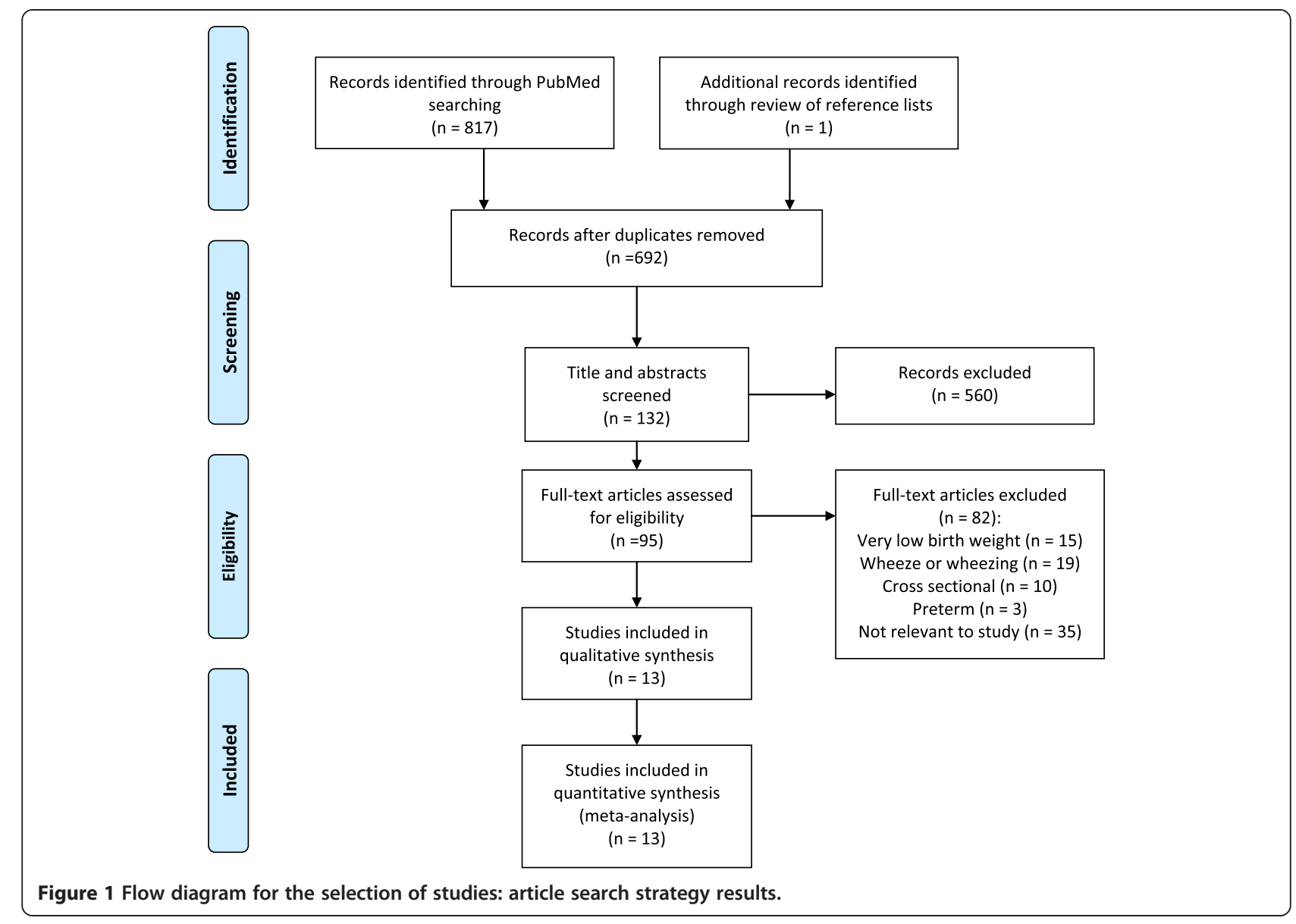

presented prevalence based on birth weight. Prevalence was converted into crude RRs, and ORs and RRs were treated as comparable measures of effect (RR). The ranges of ORs and RRs varied from 0.9 to 2.6 (Table 1).

\section{Categorical meta-analysis for low birth weight and childhood asthma}

Five of the 13 estimates were directly from the original studies, and eight were transformed from the information available to comply with our categorization used in

Table 1 Characteristics of the studies included in the analysis

\begin{tabular}{|c|c|c|c|c|c|c|}
\hline Study (reference) & Country of study, $n$. & $\begin{array}{l}\text { Primary exposure measure } \\
\text { (birth weight, g) }\end{array}$ & Effect size $(95 \% \mathrm{Cl})$ & Age at follow up (y) & Quality score & Adjusted \\
\hline Davidson [16] & England, $\mathrm{n}=248612$ & $1000-2999$ vs 3000-3999 & OR $1.2(1.1-1.3)$ & $2-10$ & 8.0 & Yes \\
\hline Chatkin [15] & Brazil, $n=981$ & $<2500$ vs $>2500$ & RR 1.32 (0.8-1.96) & $4-5$ & 5.5 & Yes \\
\hline Nepomnyaschy [19] & United States, $\mathrm{n}=1803$ & $<2500$ vs $>2500$ & RR 1.57 (1.23-1.99) & $<3$ & 6.0 & No \\
\hline Fergusson [17] & New Zealand, $\mathrm{n}=798$ & $<2500$ vs $2500-4000$ & RR 0.97 (0.6-1.58) & 16 & 5.5 & No \\
\hline Lu [18] & Taiwan, $n=69979$ & $<3000$ vs $3000-4000$ & RR 1.17 (1.09-1.27) & $13-15$ & 7.0 & No \\
\hline Yuan [26] & Denmark, $n=10190$ & $<2500$ vs $2500-4499$ & RR 0.9 (0.43-1.89) & $<12$ & 6.5 & No \\
\hline Wjst [24] & German, n = 2337 & $<2500$ vs $>2500$ & RR 1.47 (0.64-3.36) & $5-14$ & 5.0 & No \\
\hline Remes [21] & Finland, $n=4141$ & $\leq 2490$ vs $2500-4190$ & RR 1.31 (0.85-2) & 16 & 7.0 & No \\
\hline Yang [25] & United States, $n=3933$ & $<2500$ vs $>2500$ & RR 1.25 (0.73-2.15) & $6-7$ & 6.5 & No \\
\hline Rasanen [20] & Finland, $n=4502$ & $<2500$ vs $>2500$ & RR 0.97 (0.71-1.31) & 16 & 6.0 & No \\
\hline To [23] & Canada, $n=671402$ & $<2500$ vs $2500-4500$ & RR 1.18 (1.13-1.22) & 6 & 8.5 & Yes \\
\hline $\operatorname{Sin}[22]$ & Canada, $n=83595$ & $<2500$ vs $2500-4500$ & RR 1 (0.9-1.11) & 10 & 7.5 & Yes \\
\hline Bjerg [14] & Sweden, $n=3430$ & $<2500$ vs $>2500$ & OR $2.6(1.2-5.4)$ & $7-8$ & 6.0 & Yes \\
\hline
\end{tabular}


the meta-analysis. Figures 2 and 3 show forest plots, which provide study-specific and pooled RRs (95\% CIs), of development of asthma for low birth weight. When compared with normal birth weight, the pooled RRs from the fixed-effects and random-effects models were 1.162 (95\% CI, 1.128-1.197) and 1.152 (95\%, 1.082$1.222)$ for low birth weight $\left(\mathrm{I}^{2}=40.2 \%, \mathrm{P}=0.066\right)$, respectively. Both models showed similar summary effect estimates, indicating a significantly increased risk of asthma in relation to low birth weight. Table 2 shows the pooled RRs (95\% CIs) among different subgroups stratified by five main characteristics of the studies. The subgroup analyses showed an even greater effect estimate in the six studies conducted in Europe compared with other geographic areas. Additionally, subgroup analyses showed a greater effect estimate in the eight studies with a small sample size ( $<5000$ subjects) compared with those with a larger sample size, and a greater effect estimate in the seven recently published studies compared with those in the older six studies. The effect estimates stratified by study population age and adjusted RRs were similar to the overall pooled RRs.

\section{Heterogeneity and cumulative meta-analysis}

The $\mathrm{I}^{2}$ value representing the overall between-study heterogeneity was $40.2 \%(P=0.066)$, which was moderate and acceptable in the present meta-analysis. Clinical heterogeneity among subgroup studies is shown in Table 2 . Additionally, statistical heterogeneity for a greater effect estimate from subgroups stratified by geographic area, population size, and publication year was low, varying from $0 \%$ to $21.7 \%$. A meta-regression model was used to assess potential determinants of heterogeneity. Five factors (geographic area, population size, publication year, adjusted RR, and study population age) showed no statistical significance in either univariate analysis or the multivariate model $(P>0.05$, Table 3$)$.

Cumulative meta-analyses of all of the studies showed that the estimates gradually became consistent, and the corresponding CIs narrowed down in the order of publication year (Figure 4). We also performed sensitivity analysis, and the pooled results did not appear to change.

\section{Publication bias analysis}

We assessed the potential publication bias by using a funnel plot (Figure 5). The funnel plots did not show any remarkable asymmetry. Additionally, Egger's and Begg's tests showed no evident publication bias. $\mathrm{P}$ values for the two tests were 0.653 and 0.951 , respectively.

\section{Discussion}

In the present meta-analysis, 13 cohort studies and $1,105,703$ subjects were included. By conducting a systematic review, we obtained an estimate that suggests that low birth weight among children increases the risk of future asthma. Children with low birth weight have an approximately $16 \%$ higher risk of asthma compared

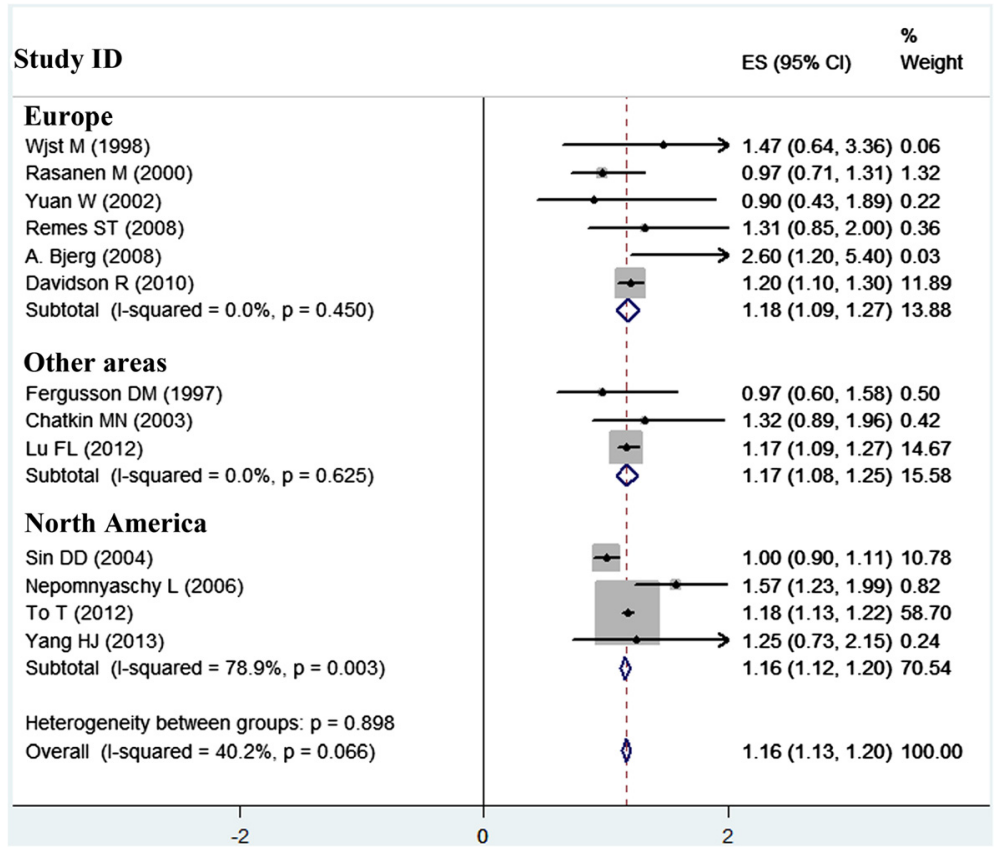

Figure 2 Meta-analysis of the effect of low birth weight on childhood asthma, and forest plots stratified by geographic area. 


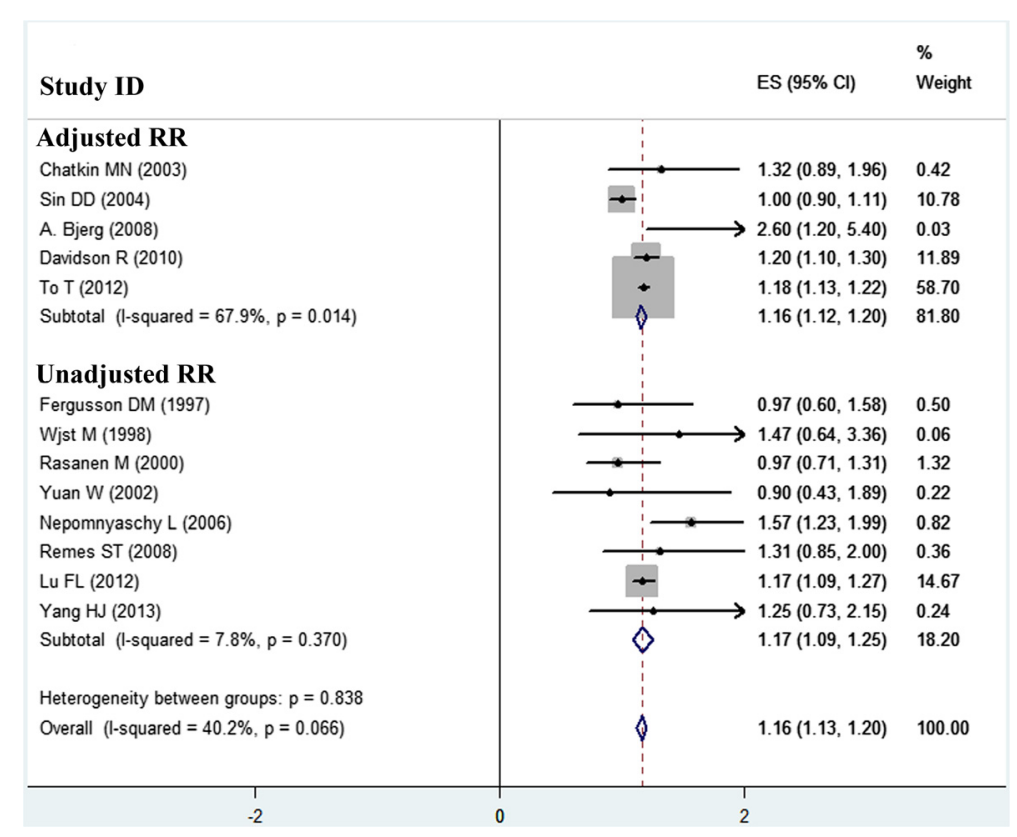

Figure 3 Forest plot of the effect of low birth weight on childhood asthma stratified by adjusted and unadjusted RRs.

with those with normal birth weight. In stratified analyses, the effect of low birth weight on childhood asthma was strong, particularly in studies conducted in Europe, those with a small sample size, and those published recently. When the moderate heterogeneity was taken into account, meta-regression analysis did not show any significant determinants.

Several limitations of this meta-analysis should be considered. First, misclassification of exposure was a potential source of bias in this systematic review,

Table 2 Pooled and subgroup analyses

\begin{tabular}{|c|c|c|c|c|c|}
\hline \multirow{2}{*}{ Stratification } & \multirow{2}{*}{$\begin{array}{l}\text { Number } \\
\text { of study }\end{array}$} & \multicolumn{2}{|c|}{ Model } & \multicolumn{2}{|c|}{ Heterogeneity statistics } \\
\hline & & Fixed-effects model (RR, 95\% CI) & Random-effects model (RR, 95\% Cl) & $1^{2}$ & $P$ value \\
\hline Overall & 13 & $1.162(1.128-1.197)$ & $1.152(1.082-1.222)$ & $40.2 \%$ & 0.066 \\
\hline \multicolumn{6}{|l|}{ Geographic area } \\
\hline Europe & 6 & $1.18(1.09-1.27)$ & $1.18(1.09-1.27)$ & $0 \%$ & 0.450 \\
\hline North America & 4 & $1.16(1.12-1.20)$ & $1.17(1.00-1.34)$ & $78.9 \%$ & 0.003 \\
\hline Other & 3 & $1.17(1.08-1.25)$ & $1.17(1.08-1.25)$ & $0 \%$ & \\
\hline \multicolumn{6}{|c|}{ Study population size } \\
\hline$<5000$ & 8 & $1.21(1.03-1.39)$ & $1.23(1.20-1.22)$ & $21.7 \%$ & 0.257 \\
\hline$\geq 5000$ & 5 & $1.16(1.12-1.20)$ & $1.14(1.07-1.21)$ & $63.1 \%$ & 0.029 \\
\hline \multicolumn{6}{|l|}{ Publication year } \\
\hline 1997-2005 & 6 & $1.01(0.91-1.10)$ & $1.01(0.91-1.10)$ & $0 \%$ & 0.857 \\
\hline 2006-2013 & 7 & $1.19(1.15-1.22)$ & $1.19(1.15-1.23)$ & $2.3 \%$ & 0.408 \\
\hline \multicolumn{6}{|l|}{ Adjusted RR } \\
\hline Yes & 5 & $1.16(1.12-1.20)$ & $1.14(1.04-1.25)$ & $67.9 \%$ & 0.014 \\
\hline No & 8 & $1.17(1.09-1.25)$ & $1.17(1.06-1.28)$ & $7.8 \%$ & 0.370 \\
\hline \multicolumn{6}{|c|}{ Study population age (year) } \\
\hline$\leq 10$ & 7 & $1.16(1.13-1.20)$ & $1.17(1.06-1.28)$ & $64.5 \%$ & 0.010 \\
\hline$>10$ & 6 & $1.15(1.07-1.23)$ & $1.15(1.07-1.23)$ & $0 \%$ & 0.692 \\
\hline
\end{tabular}


Table 3 Meta-regression analysis of the determinants of heterogeneity between study-specific effect estimates

\begin{tabular}{lccc}
\hline Determinants & \multicolumn{2}{c}{ Univariate analyses } \\
\cline { 2 - 4 } & Regression coefficient & $\mathbf{9 5 \%} \mathbf{C l}$ & P value \\
\hline Geographic area & -0.012 & $-0.155-0.131$ & 0.853 \\
Study population size & -0.00003 & $-0.0005-0.0004$ & 0.874 \\
Publication year & 0.01 & $-0.011-0.031$ & 0.330 \\
Adjusted RR & 0.035 & $-0.172-0.242$ & 0.714 \\
Study population age & -0.082 & $-0.308-0.144$ & 0.440 \\
\hline
\end{tabular}

especially because of acceptance of different definitions of low and normal birth weight. The acceptance of low birth weight, including less than $2500 \mathrm{~g}$ or $3000 \mathrm{~g}$, varied for different cohorts. Second, when the adjusted estimates were unavailable, the calculated estimates without adjustment were likely to have potential confounding. Third, restriction of analysis to articles published in English is another potential limitation. Furthermore, the effect of low birth weight on childhood asthma in the identified studies was not the primary objective, possibly leading to missing relevant data that was not evident in the title or abstract.

Asthma is a serious global health problem, and its prevalence is increasing in most countries, especially among children [2]. Meta-analyses have shown that some adverse environmental factors could be associated with the development of asthma later in life. Exposure to wood dust, and prenatal or early life antibiotic exposure increase the risk of developing childhood asthma $[5,27]$. Prenatal or early life probiotic administration reduces the risk of atopic sensitization in children, but may not reduce the risk of asthma [28]. Preterm infants have an increased risk of asthma compared with term neonates [29]. Moreover, children with a high birth weight or body weight later are at increased risk for future asthma [6]. The underlying biological mechanisms of this increased risk might include diet, gastrooesophageal reflux, mechanical effects of obesity, atopy, and hormonal influences [6]. In addition to high birth weight, our meta-analysis further indicated that low birth weight was strongly correlated with the risk of childhood asthma.

Based on the present findings, low birth weight appears to be a significant risk factor for childhood asthma. If low birth weight can be considered as a modifiable risk factor, prevention of low birth weight could be associated with a decrease in the incidence of asthma. The purpose of this study was to evaluate the effect of low birth weight on the development of asthma later in life. In the present meta-analysis, we found that children with low birth weight had an approximately $16 \%$ higher risk of asthma. However, this association may be complicated by the fact that birth weight is not the only contributor to development of asthma. The effect of low

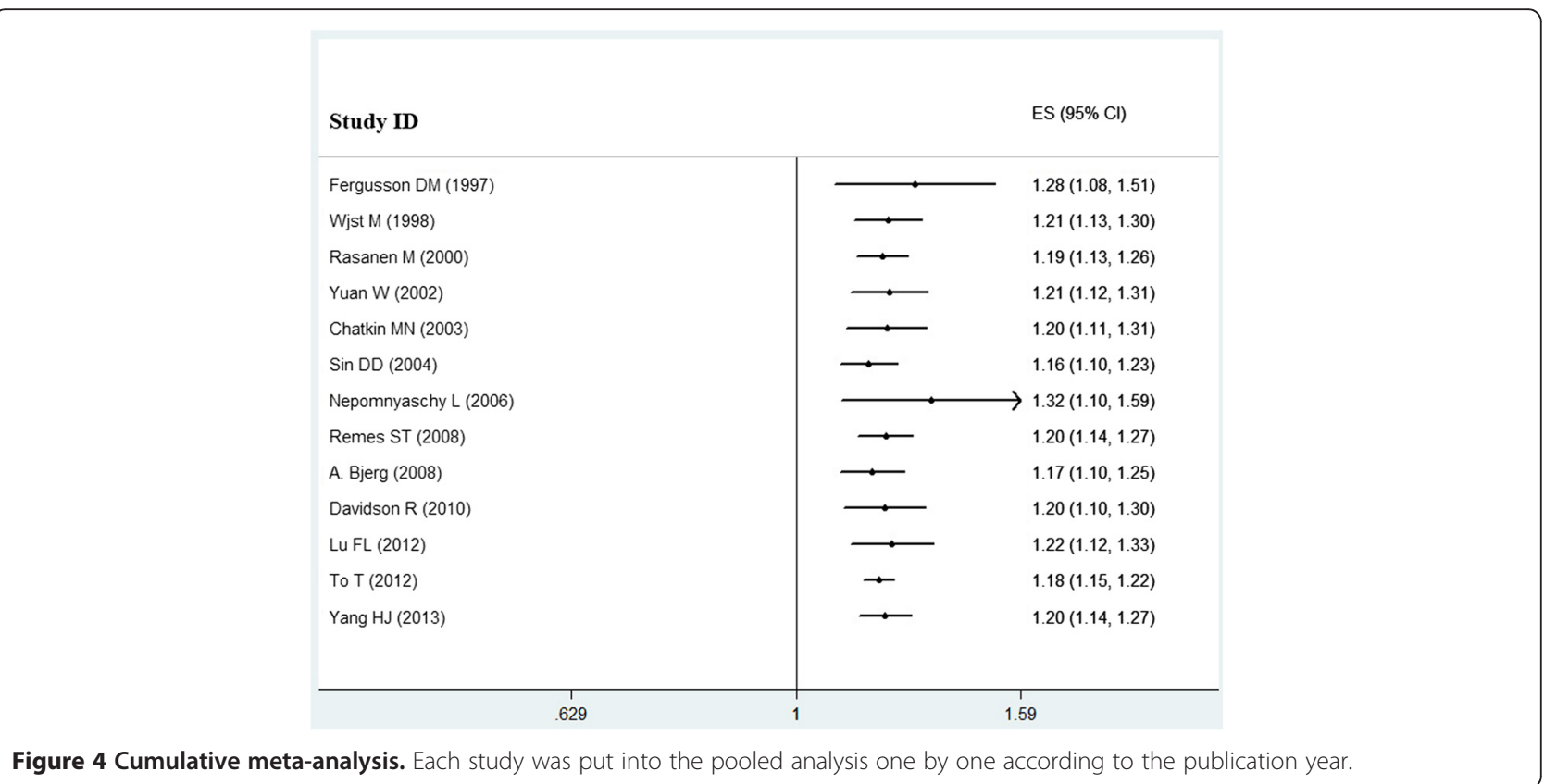




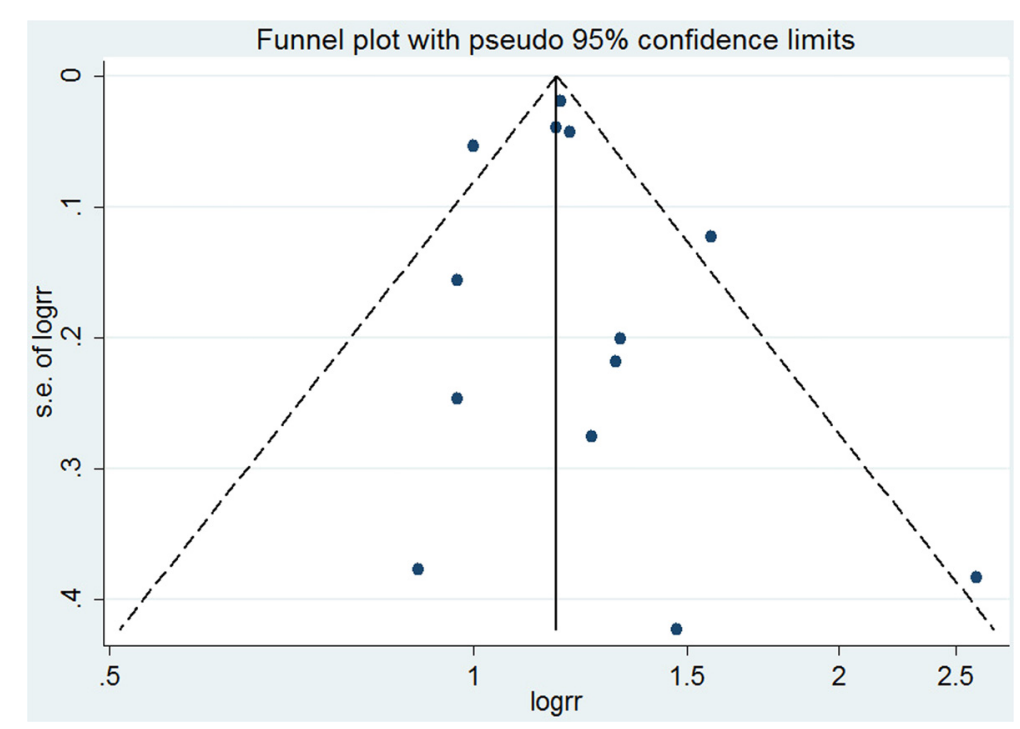

Figure 5 Funnel plot of the effect estimates ( $\log$ RR) by their SE (standard error of log RR). The vertical line indicates the summary effect estimate and the corresponding pseudo 95\% confidence limits converging as a function of the SE of the effect estimate.

birth weight on asthma is likely to be equally important compared with other risk factors, such as a family history of asthma and air pollution [3,30].

The potential mechanisms of the association between low birth weight and an increased risk of childhood asthma are not fully understood. There is a wealth of epidemiological evidence that lower birth weight is strongly correlated with an increased risk of adult diseases, such as hypertension, type 2 diabetes mellitus, and cardiovascular disease [7,31]. This phenomenon of fetal origins of adult disease is strongly associated with fetal insults to epigenetic modifications of genes $[7,32,33]$. Therefore, we speculate that epigenetic regulation may be involved in this mechanism of an increased risk of childhood asthma followed by low birth weight. Children with low birth weight could have varying degrees of problems with lung development, which would cause a greater sensitivity of an individual to external environmental stimuli and result in an increased risk of asthma. Additionally, children with low birth weight may be more likely to experience exposure to antibiotics, which has been previously shown to increase the risk of asthma [5].

In our analysis, significant differences were also observed across subgroups stratified by geographic area, population size, and publication year. Although the overall between-study heterogeneity was moderate, clinical heterogeneity among subgroup studies was low, indicating a greater effect estimate stratified by subgroup. Furthermore, these stratified factors were not found to be significant potential determinants in meta-regression. As in every meta-analysis, the quality of the individual studies may largely influence the review results. In the present analysis, all of the included studies possessed a high quality score. This heterogeneity in the present meta-analysis was acceptable.

\section{Conclusions}

In summary, the weight of evidence shows that low birth weight significantly increases the risk of childhood asthma. The potential mechanisms underlying this association are not well understood. With regard to the relation between birth weight and asthma, special attention should be paid to the effect of different birth weights in children. Large-sample, well-designed, prospective cohort studies, should be performed in the future.

\section{Competing interests}

The authors declare that they have no competing interests.

\section{Authors' contributions}

All authors contributed to the design and analysis. XFX and ZMC had primary responsibility for study design, data analysis, and writing, and editing the manuscript. YJL, YJS, JLL, and LFT participated in the study design, data collection, and analysis. XFX and YJL participated in statistical analysis and manuscript editing. All authors read and approved the final manuscript.

\section{Acknowledgements}

We thank Dr. Ming-Juan Jin for statistical support. This work was supported by grants from the National Natural Science Foundation of China (No. 81270723), and Zhejiang Provincial Health High-Level Personnel Training Project of China (Yi Tan Xin Xiu).

\section{Author details}

'Department of Pulmonology, The Children's Hospital, Zhejiang University School of Medicine, Hangzhou 310003, China. ${ }^{2}$ Department of Epidemiology and Health Statistics, School of Public Health, Zhejiang University, Hangzhou, China. 
Received: 12 March 2014 Accepted: 9 October 2014

Published: 23 October 2014

\section{References}

1. To T, Stanojevic S, Moores G, Gershon AS, Bateman ED, Cruz AA, Boulet LP: Global asthma prevalence in adults: findings from the cross-sectional world health survey. BMC Public Health 2012, 12:204.

2. Bateman ED, Hurd SS, Barnes PJ, Bousquet J, Drazen JM, FitzGerald M, Gibson P, Ohta K, O'Byrne P, Pedersen SE, Pizzichini E, Sullivan SD, Wenzel $\mathrm{SE}, \mathrm{Zar} \mathrm{HJ}$ : Global strategy for asthma management and prevention: GINA executive summary. Eur Respir J 2008, 31(1):143-178.

3. Vernon MK, Wiklund I, Bell JA, Dale P, Chapman KR: What do we know about asthma triggers? A review of the literature. J Asthma 2012, 49(10):991-998.

4. Patelarou $\mathrm{E}$, Chochlidaki M, Vivilaki V, Brokalaki H: Is there a link between wheezing in early childhood and adverse birth outcomes? A systematic review. Int J Environ Res Public Health 2009, 6(11):2752-2761.

5. Murk W, Risnes KR, Bracken MB: Prenatal or early-life exposure to antibiotics and risk of childhood asthma: a systematic review. Pediatrics 2011, 127(6):1125-1138.

6. Flaherman V, Rutherford GW: A meta-analysis of the effect of high weight on asthma. Arch Dis Child 2006, 91(4):334-339.

7. Barker DJP: Fetal and infant origins of adult disease. Monschr Kinderheilkd 2001, 149:S2-S6

8. Shaheen SO, Sterne JA, Montgomery SM, Azima H: Birth weight, body mass index and asthma in young adults. Thorax 1999, 54(5):396-402

9. Vrijlandt EJ, Gerritsen J, Boezen HM, Duiverman EJ, Dutch P-CSG: Gender differences in respiratory symptoms in 19-year-old adults born preterm. Respir Res 2005, 6:117.

10. Higgins JP, Thompson SG, Deeks JJ, Altman DG: Measuring inconsistency in meta-analyses. BMJ 2003, 327(7414):557-560.

11. Egger M, Davey Smith G, Schneider M, Minder C: Bias in meta-analysis detected by a simple, graphical test. BMJ 1997, 315(7109):629-634.

12. Begg CB, Mazumdar M: Operating characteristics of a rank correlation test for publication bias. Biometrics 1994, 50(4):1088-1101.

13. Duval S, Tweedie R: Trim and fill: a simple funnel-plot-based method of testing and adjusting for publication bias in meta-analysis. Biometrics 2000, 56(2):455-463.

14. Bjerg A, Ronmark E: Asthma in school age: prevalence and risk factors by time and by age. Clin Respir J 2008, 2(Suppl 1):123-126.

15. Chatkin MN, Menezes AM, Victora CG, Barros FC: High prevalence of asthma in preschool children in Southern Brazil: a population-based study. Pediatr Pulmonol 2003, 35(4):296-301.

16. Davidson R, Roberts SE, Wotton CJ, Goldacre MJ: Influence of maternal and perinatal factors on subsequent hospitalisation for asthma in children: evidence from the Oxford record linkage study. BMC Pulm Med 2010, 10:14.

17. Fergusson DM, Crane J, Beasley R, Horwood LJ: Perinatal factors and atopic disease in childhood. Clin Exp Allergy 1997, 27(12):1394-1401.

18. Lu FL, Hsieh CJ, Caffrey UL, Lin MH, Lin YS, Lin CC, Tsai MS, Ho WC, Chen PC, Sung FC, Lin RS: Body mass index may modify asthma prevalence among low-birth-weight children. Am J Epidemiol 2012, 176(1):32-42.

19. Nepomnyaschy L, Reichman NE: Low birthweight and asthma among young urban children. Am J Public Health 2006, 96(9):1604-1610.

20. Rasanen M, Kaprio J, Laitinen T, Winter T, Koskenvuo M, Laitinen LA: Perinatal risk factors for asthma in Finnish adolescent twins. Thorax 2000, 55(1):25-31

21. Remes ST, Patel SP, Hartikainen AL, Jarvelin MR, Pekkanen J: High birth weight, asthma and atopy at the age of $16 \mathrm{yr}$. Pediatr Allergy Immunol 2008, 19(6):541-543.

22. Sin DD, Spier S, Svenson LW, Schopflocher DP, Senthilselvan A, Cowie RL, Man SF: The relationship between birth weight and childhood asthma: a population-based cohort study. Arch Pediatr Adolesc Med 2004, 158(1):60-64.

23. To T, Guan J, Wang C, Radhakrishnan D, McLimont S, Latycheva O, Gershon AS: Is large birth weight associated with asthma risk in early childhood? Arch Dis Child 2012, 97(2):169-171.

24. Wjst M, Popescu M, Trepka MJ, Heinrich J, Wichmann HE: Pulmonary function in children with initial low birth weight. Pediatr Allergy Immunol 1998, 9(2):80-90
25. Yang HJ, Qin R, Katusic S, Juhn YJ: Population-based study on association between birth weight and risk of asthma: a propensity score approach. Ann Allergy Asthma Immunol 2013, 110(1):18-23.

26. Yuan W, Basso O, Sorensen HT, Olsen J: Fetal growth and hospitalization with asthma during early childhood: a follow-up study in Denmark. Int J Epidemiol 2002, 31(6):1240-1245.

27. Perez-Rios M, Ruano-Ravina A, Etminan M, Takkouche B: A meta-analysis on wood dust exposure and risk of asthma. Allergy 2010, 65(4):467-473.

28. Elazab N, Mendy A, Gasana J, Vieira ER, Quizon A, Forno E: Probiotic administration in early life, atopy, and asthma: a meta-analysis of clinical trials. Pediatrics 2013, 132(3):e666-e676.

29. Jaakkola JJ, Ahmed P, leromnimon A, Goepfert P, Laiou E, Quansah R, Jaakkola MS: Preterm delivery and asthma: a systematic review and meta-analysis. J Allergy Clin Immunol 2006, 118(4):823-830.

30. Arruda LK, Sole D, Baena-Cagnani CE, Naspitz CK: Risk factors for asthma and atopy. Curr Opin Allergy Clin Immunol 2005, 5(2):153-159.

31. Xu XF, Du LZ: Epigenetics in neonatal diseases. Chin Med J (Engl) 2010, 123(20):2948-2954

32. Xu XF, Cheng F, Du LZ: Epigenetic regulation of pulmonary arterial hypertension. Hypertens Res 2011, 34(9):981-986.

33. Xu XF, Lv Y, Gu WZ, Tang LL, Wei JK, Zhang LY, Du LZ: Epigenetics of hypoxic pulmonary arterial hypertension following intrauterine growth retardation rat: epigenetics in PAH following IUGR. Respir Res 2013, 14:20.

doi:10.1186/1471-2431-14-275

Cite this article as: Xu et al:: Effect of low birth weight on childhood asthma: a meta-analysis. BMC Pediatrics 2014 14:275.

\section{Submit your next manuscript to BioMed Central and take full advantage of:}

- Convenient online submission

- Thorough peer review

- No space constraints or color figure charges

- Immediate publication on acceptance

- Inclusion in PubMed, CAS, Scopus and Google Scholar

- Research which is freely available for redistribution

Submit your manuscript at www.biomedcentral.com/submit
C BioMed Central 